\title{
Assessment of Tidal Breathing Patterns for Monitoring of Bronchial Obstruction in Infants
}

\author{
P. BANOVCIN. J. SEIDENBERG, AND H. VON DER HARDT
}

Department of Pediatric:, Medical Faculty of Comenius University, Martin, Slovakia [P.B.] and Department of Pediatrics, Hannover Medical Sihool, Hannover, Federal Republic of Germany [J.S., H.V.D.H.I

\begin{abstract}
Two parameters of tidal breathing, the ratio of time to reach peak tidal expiratory flow to the total expiratory time ('Ime/TE) and the ratio of volume exhaled at peak tidal expiratory flow to the total exhaled volume (dV/VT) were used to assess lung function in 21 sedated infants (aged 6-14 mo) with different degrees of airway obstruction. These parameters were compared with airway resistance as percentage predicted (Raw\%) and maximum expiratory flow at functional residual capacity corrected for lung volume ( $\left.\dot{V}_{\operatorname{mix}} \mathrm{FRC} / \mathrm{TGV}\right)$. $\dot{\mathrm{V}}_{\max } \mathrm{H} / \mathrm{KC} / \mathrm{I} G \mathrm{~V}$ values corrclated significantly with Tme/TE $(r=0.630, p=0.002)$ as well as with $\mathrm{dV} / \mathrm{VT}(r=0.728, p-0.001)$. Raw\% values showed only a weak correlation with dV/VT $(r=-0.435, p=$ (0.048). We conclude that Tme/Te and dV/V'I are both able to detcct airway obstruction in infants and that these parameters corrclatc much better with the forced expiratory flow values obtained by the rapid thoracic compression method than with airway resistance, determined by body plethysmography.

\section{Abbreviations}

dV/VT, ratio of volume exhaled at peak tidal expiratory flow to the total expiratory volume

Raw, airway resistance

Raw\%, airway resistance as percentage of the predicted values

TGV, thoracic gas volume

FRC pleth, functional residual capacity measured by plcthysmography

TE, total expiratory time

Tme/TE, ratio of expiratory time to reach peak tidal cxpiratory flow to the total expiratory time

$\dot{\mathbf{V}}_{\text {max }}$ FRC, maximum expiratory flow at functional residual capycity

$\dot{\mathbf{V}}_{\max }$ FRC/TGV, maximum expiratory flow at functional residual capacity corrected for lung volume
\end{abstract} (Pediatr Res 38: 218-220, 1995)

During the past three decades pulmonary function tests have been successfully adapted or newly developed to measure lung function in neonates and infants. However, most methods still require sedation, expensive equipment, and highly skilled technicians. Therefore, such investigations have been restricted to few specialized research centers $(1,2)$.

Recently, the measurement of tidal breathing parametcrs by so-called body surface techniques was suggested to simplify lung function testing in infants and young children. However, there is still a lack of studies comparing standard lung function parameters with the recently described parameters of tidal expiratory flow. In patients with airway obstruction, a rapid rise to peak tidal expiratory flow has been observed $(3,4)$ Thereforc, the time necessary to reach peak expiratory flow expressed as Tme/TE as well as the volume expired at peak

Reccived December 23, 1993; accepted February 9. 1945

Correspondence and reprint requests: Dr. Horst von der Hardt. Department of Pediat rics, Hannover Medical School, Postbox 610180, D-30625 Hannover, Federal Republic of (icrmany.

Supported by the Alexander von Humboldt Foundation expiratory flow expressed as $\mathrm{dV} / \mathrm{TV}$ were proposed as simple indices of airway obstruction (4-6).

In the present study, we compared Tme/IE and dV/VT with Raw $\%$ and $\dot{V}_{\text {max }}$ FRC/TGV to evaluate their potential to assess airway obstruction in infants.

\section{METHODS}

In 21 infants aged 6-14 mo (median $9.3 \mathrm{mo}$ ) with a mean body weight of $8.62 \mathrm{~kg}$ (range $5.6-11.0 \mathrm{~kg}$ ) measurements were obtained. All infants suffered from obstructive airway diseases (Table 1) and received standard lung function tests for diagnostic reasons. All parents gave informed consent.

The infants were sedated with chloral hydrate $(50-80 \mathrm{mg}$ $\mathrm{kg}$, orally). Studies were performed during quiet sleep in the supine position with the neck slightly extended. Raw and TGV werc measured in a volume constant baby body plethysmograph (Fenyves and Gut, Switzerland) under body temperature, standard pressure, and saturated water vapor (gas) conditions. Partial expiratory flow-volume curves were obtained by the rapid thoracic compression technique (7-9) using an inflatable plastic bag wrapped around the infants chest and abdomen. 
Table 1. Subject characteristics

\begin{tabular}{clccl}
\hline Subject & Sex & Age (mo) & Weight $(\mathrm{kg})$ & Diagnosis* \\
\hline 1 & M & 8 & 9.9 & WB \\
2 & F & 12 & 8.8 & WB \\
3 & M & 11 & 9.5 & WB \\
4 & M & 11 & 10.5 & WB \\
5 & M & 7 & 7.2 & LS \\
6 & M & 14 & 10.0 & WB \\
7 & F & 11 & 9.0 & WB \\
8 & M & 9 & 6.9 & BPD \\
9 & M & 7 & 8.5 & LS \\
10 & M & 7 & 9.1 & WB \\
11 & F & 6 & 6.0 & BL \\
12 & M & 6 & 9.2 & TS \\
13 & F & 10 & 9.0 & WB \\
14 & F & 12 & 9.2 & CF \\
15 & F & 7 & 5.6 & BPD \\
16 & M & 10 & 11.0 & WB \\
17 & M & 14 & 8.3 & WB \\
18 & F & 11 & 7.6 & BPD \\
19 & F & 6 & 7.2 & WB \\
20 & M & 8 & 9.1 & WB \\
21 & F & 9 & 8.0 & BPD \\
\hline
\end{tabular}

* Clinical diagnoses: WB, wheezy bronchitis; LS, laryngeal stridor; BPD, bronchopulmonary dysplasia; BL, bronchiolitis; TS, tracheal stenosis; $\mathrm{CF}$, cystic fibrosis.

Five maneuvers at optimal compression pressure were obtained, and the mean of the three best values of maximum flows at functional residual capacity $\left(\dot{V}_{\max } F R C\right)$ was used for analysis after correction for lung size ( $\left.\dot{\mathrm{V}}_{\max } \mathrm{FRC} / \mathrm{TGV}\right)$.

At least $5 \mathrm{~min}$ after these measurements, tidal breathing parameters were obtained using pneumotachography and stored on a magnetic tape recorder (Sony three head, stereo tape corder). For analysis, flow curves and flow-volume curves were plotted with reduced speed on an X-Y recorder (HewlettPackard 741A). At least 10 breaths were used to calculate mean Tme/TE as well as the mean value of $\mathrm{dV} / \mathrm{VT}$ (4). The correlation between different variables was calculated using linear regression analysis. Statistical significance was defined as $p=0.05$.

\section{RESULTS}

Raw\% values ranged from 81 to $280 \%$ (mean $165.7 \%$ ) and $\dot{\mathrm{V}}_{\text {max }} \mathrm{FRC} / \mathrm{TGV}$ values ranged from 0.08 to $1.28 \mathrm{~mL} / \mathrm{s}$ per $\mathrm{mL}$ (mean $0.448 \mathrm{~mL} / \mathrm{s}$ per $\mathrm{mL}$ ).

No significant correlation was found between Tme/TE (range 0.16 to 0.36 ) and Raw\% ( $r=-0.089, p=0.695$, Fig. $1 A)$. An inverse relationship was just significant between $\mathrm{dV} / \mathrm{VT}$ (range 0.18 to 0.36 ) and Raw\% ( $r=-0.435, p=$ 0.048 , Fig. $1 B$ ).

A
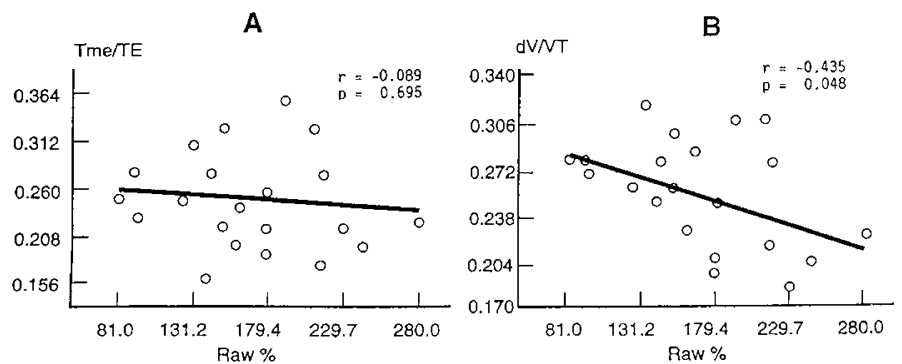

Figure 1. Correlation between Raw\% and Tme/TE $(A)$ and dV/VT $(B)$.
Both Tme/TE $(r=0.630, p=0.002)$ and $\mathrm{dV} / \mathrm{VT}(r=$ $0.728, p=0.001$ ) correlated well with $\dot{\mathrm{V}}_{\max }$ FRC/TGV (Fig. 2, $A$ and $B$ ). There seems to be a more sensitive change of $\mathrm{dV} / \mathrm{VT}$ compared with Tme/TE with decreasing $\dot{\mathrm{V}}_{\max }$ FRC/TGV.

\section{DISCUSSION}

Both parameters of tidal breathing, Tme/TE as well as $\mathrm{dV} / \mathrm{VT}$ are able to detect changes in the airway caliber. They correlated well with measurements obtained using more sophisticated and expensive standard lung function methods such as the rapid thoracic compression technique combined with body plethysmography.

Similar to our results in infants, Morris and Lane (4) demonstrated that in adults and school aged children both Tme/TE and $\mathrm{dV} / \mathrm{VT}$ were significantly lower in subjects with obstructive airway disease. These values correlated well with the forced expiratory volume at $1 \mathrm{~s}$ predicted and with specific airway conductance. Morgan et al. (10) reported that infants suffering from bronchopulmonary dysplasia also had significantly lower values for Tme/TE than did healthy infants.

Similar results were reported recently by Clarke et al. (11) in infants with chronic obstructive lung disease, whereas there were no significant differences between healthy and mildly asthmatic infants. It was concluded that Tme/TE is an insensitive parameter to describe airway function compared with $\dot{\mathrm{V}}_{\text {max }}$ FRC. In our group of infants, Tme/Te values were consistently low only with $\dot{\mathrm{V}}_{\max } \mathrm{FRC} / \mathrm{TGV}$ values below $0.5 \mathrm{~mL} / \mathrm{s}$ per $\mathrm{mL}$. Furthermore, Aston et al. (12) found no significant change of Tme/TE in infant bronchial challenge tests although $\dot{\mathrm{V}}_{\text {max }}$ FRC significantly decreased by $43 \%$. They suggested that the infants had adopted a strategy of active expiration in response to bronchial challenge.

Up to now, the exact mechanisms producing the decrease of Tme/TE and $\mathrm{dV} / \mathrm{VT}$ are not known. Tme/TE may reflect the neuromuscular response to changes in passive respiratory system time constant and resting volume $(13,14)$. Morris and Lane (4) suggested that in patients with airway obstruction the need for active braking during expiration may be diminished, resulting in an early peak of expiratory flow. In addition, because of the high expiratory time constant, TE must be long to allow exhalation to be completed, which results in Tme/TE being very low. However, as described by Seidenberg et al. (15), some infants suffering from acute bronchiolitis tend to breathe at higher lung volumes to reduce flow limitation, thereby avoiding a long expiratory time constant. This alternative response to airway obstruction may explain normal tidal

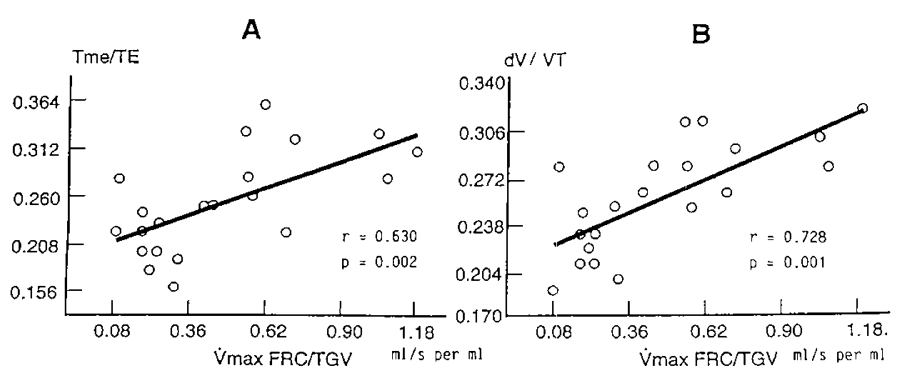

Figure 2. Correlation between $\dot{\mathrm{V}}_{\max } \mathrm{FRC} / \mathrm{TGV}$ and Tme/TE $(A)$ and dV/VT $(B)$. 
breathing parameters in spite of decreased values for $\dot{\mathrm{V}}_{\max } \mathrm{FRC}$ or $\dot{\mathrm{V}}_{\max } \mathrm{FRC/TGV}$.

In our study Tme/TE and dV/VT correlated significantly with $\dot{\mathrm{V}}_{\max } \mathrm{FRC/TGV}$, but only $\mathrm{dV} / \mathrm{VT}$ had a close relationship to Raw\%. Airway resistance is mainly determined by the central airways, and although some controversy exists regarding the proper methodology for the rapid thoracic compression technique $(16,17), \dot{V}_{\max } \mathrm{FRC}$ is generally agreed to reflect mainly the patency of the small airways (18). Therefore, our data might suggest that the decrease of Tme/TE and dV/VT indicate mainly changes in the smaller airways or in the lung parenchyma. This assumption is supported by the studies of Martinez et al. $(5,19)$, which showed decreased values for Tme/TE and $\dot{\mathrm{V}}_{\max } \mathrm{FRC}$ in young infants who later developed wheezing illnesses.

\section{CONCLUSION}

In conclusion, our results suggest that both tidal breathing parameters, Tme/TE and dV/VT, may be able to assess airway obstruction in infants. Both parameters may not be as sensitive as $\dot{\mathrm{V}}_{\text {max }} \mathrm{FRC/TGV}$ due to compensatory respiratory control mechanisms. Tme/TE as well as $\mathrm{dV} / \mathrm{VT}$ are correlating better with measures of peripheral airway obstruction $\left(\dot{V}_{\max } \mathrm{FRC} /\right.$ TGV) than with Raw, reflecting mainly central airway patency.

Acknowledgments. The authors thank Heidi Schulenburg and Delef Heinrich for their skillful assistance.

\section{REFERENCES}

1. Stocks J 1991 Recent advances in the assessment of lung function in infants. Pneumologie 45:881-886
2. Chovan L, Redhammer R, Mihalec L, Ulrich L, Malik E 1988 Bronchial hyperreactivity in nonasthmatic individuals. Eur Respir $J$ 1(suppl 2):381(abstr)

3. Phelan PD, Williams HE, Freeman M 1968 The disturbance of ventilation in acute viral bronchiolitis. Aust Pediatr J 4:96-104

4. Morris MJ, Lane DJ 1981 Tidal expiratory flow patterns in airway obstruction. Thorax 36:135-142

5. Martinez FD, Morgan WJ, Wright AL, Holberg CJ, Taussig LM, GHMA Pediatricians 1988 Diminished lung function as a predisposing factor for wheezing respiratory illness in infant. N Engl J Med 319:1112-1117

6. Cutrera R, Filtchev SI, Merolla R, Willim G, Haluszka J, Ronchetti R 199I Analysis of expiratory pattern for monitoring bronchial obstruction in school-age children. Pediatr Pulmonol 10:6-10

7. Masters IB, Seidenberg J, Hudson I, Phelan PD, Olinsky A 1987 Longitudinal study of lung mechanics in normal infants. Pediatr Pulmonol 3:3-7

8. Taussig LM, Landau LI, Godfrey S, Arad I 1982 Determinants of forced expiratory flows in newborn infants. J Appl Physiol 53:1220-1227

9. Tepper RS, Morgan WJ, Cota K, Wright A, Taussig LM, GHMA Pediatricians 1986 Physiologic growth and development of the lung during the first year of life. Am Rev Respir Dis 134:513-519

10. Morgan WJ, Tepper RS, Wilcox E, Taussig LM, GHMA Pediatricians 1984 Shape and moment analysis of tidal expiration in normal and bronchopulmonary dysplasia infants. Am Rev Respir Dis 129(suppl):A215(abstr)

11. Clarke J, Aston H, Silverman M 1994 Evaluation of a tidal expiratory flow index in healthy and diseased infants. Pediatr Pulmonol 17:285-290

12. Aston H, Clarke J, Silverman M 1994 Are tidal breathing indices useful in infant bronchial challenge tests? Pediatr Pulmonol 17:225-230

13. Remmers JE, Bartlett D 1977 Reflex control of expiratory airflow and duration. J Appl Physiol 42:80-87

14. Davis GM, Bureau MA 1987 Pulmonary and chest wall mechanics in the control of respiration in the newborn. Clin Perinatol 14:551-579

15. Seidenberg J, Masters IB, Hudson I, Olinsky A, Phelan PD 1989 Disturbance in respiratory mechanics in infants with bronchiolitis. Thorax 44:660-667

16. LeSouef PN, Hughes DM, Landau LI 1988 Shape of forced expiratory flow-volume curves in intants. Am Rev Respir Dis 138:590-597

17. Silverman M, Prendville A, Green S 1986 Partial Expiratory flow-volume curves in infancy: technical aspects. Bull Eur Physiopathol Respir 22:257-262

18. Hanrahan JP, Tager IB, Castile RG, Segal MR, Weiss ST, Spizer FE 1990 Pulmonary function measures in healthy infants. Am Rev Respir Dis 141:1127-1135

19. Martinez FD, Morgan WJ, Wright AL, Holberg C, Taussig LM, GHMA Personnel 1991 Initial airway function is a risk factor for reccurent wheezing respiratory illnesses during the first three years of life. Am Rev Respir Dis 143:312-316 